\title{
Term birth weight and ambient air pollutant concentrations during pregnancy, among women living in Monroe County, New York
}

\author{
Rui $\mathrm{Li}^{1} \cdot$ Philip K. Hopke ${ }^{1} \cdot$ Ann Dozier ${ }^{1} \cdot$ Sally W. Thurston ${ }^{2} \cdot$ Kelly Thevenet-Morrison $^{1} \cdot$ Daniel $^{C_{r o f t}}{ }^{3} \cdot$ \\ Mauro Masiol $^{1} \cdot$ Stefania Squizzato $^{1} \cdot$ David Chalupa $^{4}$ - David Q. Rich ${ }^{1,3,4}$
}

Received: 26 October 2018 / Revised: 23 February 2019 / Accepted: 23 February 2019 / Published online: 2 April 2019

(c) The Author(s) 2019. This Article is published with open access

\begin{abstract}
Increased ambient air pollutant concentrations during pregnancy have been associated with reduced birth weight, but the etiologically relevant pregnancy time window(s) is/are unclear. In 76,500 singleton births in Monroe County, NY (2005-2016), who were 37-42 gestational weeks at delivery, we used generalized linear models to regress term birth weight against mean gestational month pollutant concentrations, adjusting for mean temperature, and maternal, infant, and medical service use characteristics. Overall, there were no clear patterns of term birth weight change associated with increased concentrations of any pollutant across gestational months. However, among Hispanic women only, increases in all pollutants, except $\mathrm{O}_{3}$, in multiple gestational months, were associated with decreased term birth weight. Each $3.25 \mu \mathrm{g} / \mathrm{m}^{3}$ increase in $\mathrm{PM}_{2.5}$ concentration in the $6^{\text {th }}$ gestational month was associated with a $-20.4 \mathrm{~g}(95 \% \mathrm{CI}=-34.0,-6.8)$ reduction in term birth weight among Hispanic women, but a $4.1 \mathrm{~g}(95 \% \mathrm{CI}=-2.5,10.8)$ increase among non-Hispanic mothers $(p$ for interaction $<0.001$ ). Although ambient air pollutant concentrations during pregnancy were not associated with reduced term birth weight among women of all ethnicities living in Monroe County, this observed association in Hispanic mothers may be a result of less exposure misclassification and bias (due to closer residential proximity to the monitoring site).
\end{abstract}

Keywords: Ambient air pollution $\cdot$ Term birth weight $\cdot$ Epidemiology

\section{Introduction}

Birth weight is an important determinant of physical, psychological, and behavioral outcomes in later life [1] with some studies reporting associations between increased

Supplementary information The online version of this article (https:// doi.org/10.1038/s41370-019-0131-8) contains supplementary material, which is available to authorized users.

David Q. Rich

david_rich@urmc.rochester.edu

1 Department of Public Health Sciences, University of Rochester Medical Center, Rochester, NY, USA

2 Department of Biostatistics and Computational Biology, University of Rochester Medical Center, Rochester, NY, USA

3 Department of Medicine, University of Rochester Medical Center, Rochester, NY, USA

4 Department of Environmental Medicine, University of Rochester Medical Center, Rochester, NY, USA ambient air pollutant concentrations during pregnancy and reduced birth weight or an increased risk of low birth weight (LBW) $(<2500 \mathrm{~g})$ among term births ( $>37$ weeks gestation at birth) [2-8], but not others [9]. In an international meta-analysis of 14 studies, increased mean concentrations of particulate air pollution across the entire pregnancy were associated with increased odds of low term birth weight $(<2500 \mathrm{~g})$ [5]. However, because this metaanalysis and these 14 studies did not identify specific gestational age windows (e.g., early or late pregnancy) during which exposure to air pollution was consistently associated with LBW, understanding potential mechanisms of any pollutant effect on fetal growth has been difficult [10]. In a study of pregnant Beijing women before, during, and after the 2008 Beijing Olympics, we found that infants of Beijing residents, whose $8^{\text {th }}$ month of gestation occurred during the 2008 Olympics and its large air pollution reductions, were heavier ( $23 \mathrm{~g} ; 95 \% \mathrm{CI}=5,40)$, on average, than infants whose $8^{\text {th }}$ month occurred during the same 2007 and 2009 calendar dates. Further, incremental increases in $\mathrm{PM}_{2.5}, \mathrm{CO}, \mathrm{SO}_{2}$, and $\mathrm{NO}_{2}$ concentrations 
during the $8^{\text {th }}$ month of pregnancy were associated with 17-34 $\mathrm{g}$ decreases in term birth weight, respectively [9]. Although this study suggested late pregnancy air pollution exposure was important with regard to their effects on term birth weight and fetal growth, confirmation is needed in US cities with lower air pollution concentrations.

Increased risks of preterm birth [11] and preeclampsia, among women living in Monroe County, New York [12], have been associated with ambient concentrations of PM and gaseous pollutants during pregnancy, but associations with term birth weight have not been examined. Using a multi-year dataset of all births to women living in Monroe County and ambient pollutant concentrations measured at a central monitoring station in Rochester, NY, we hypothesized that increased mean pollutant concentrations in gestational months 7-9 (i.e., late pregnancy) would be associated with reduced term birth weight among term births. We then explored whether those associations were different by season, maternal employment, ethnicity, pregnancy complications, and infant gender.

\section{Material and methods}

\section{Study population}

We used maternal and infant data obtained from the Finger Lakes Region Perinatal Data System (FLRPDS), a collection of birth certificates and supplemental questionnaire data for births in the nine-county Finger Lakes region in New York State. Birth registrars at each hospital obtained data from mothers through interviews or surveys and abstracted data from mothers' and infants' medical (including prenatal) records. We included only singleton births to women residing in Monroe County at the time of birth from 1 January 2005 to 31 December 2016, with a gestational age of 37-42 completed weeks and a birth weight $\geq 500 \mathrm{~g}$.

From the FLRPDS, we extracted data on infant and maternal characteristics, pregnancy complications, and medical service-related information. We also obtained information on the date of the last menstrual period (LMP). Gestational age was calculated primarily based on LMP, with clinical estimates used for those subjects missing the LMP date. We estimated the beginning and ending date of each gestational month (here, each month was 31 days), and used this to calculate mean pollutant concentrations for each gestational month. The mean pollutant concentrations for the last month was calculated for the last 31 days before the date of delivery. The primary outcome was term birth weight (in grams), but we also defined LBW as a term birth weight $<2500 \mathrm{~g}$. The study was approved by the University of Rochester Medical Center Research Subjects Review Board.

\section{Air pollution and weather data}

Hourly concentrations of air pollutants were collected from the New York State Department of Environmental Conservation (NYSDEC) site in Rochester. This site is adjacent to two major highways (I-490 and I-590) and State Route 96 on the east side of Rochester and measures hourly mass concentrations of fine particles $\left(\mathrm{PM}_{2.5}\right.$, aerodynamic diameter $<2.5 \mu \mathrm{m}$ ), number concentrations of ultrafine particles (UFP, particles $<100 \mathrm{~nm}$ ) and accumulation mode particles (AMP, particles with diameters of 100-470 nm), black carbon (BC, a marker of traffic pollution), sulfur dioxide $\left(\mathrm{SO}_{2}\right)$, and ozone $\left(\mathrm{O}_{3}\right)$. Temperature and relative humidity data measured at the Rochester International Airport were obtained from the National Oceanic and Atmospheric Administration (NOAA) National Climate Data Center. For each study subject's gestational month of pregnancy, we calculated mean pollutant concentrations, temperature and relative humidity if at least $75 \%$ of the hourly pollutant, temperature, or humidity values during the specified gestational month period were reported. We then used these monthly pollutant concentrations and weather characteristics in the statistical analyses described below.

\section{Study design and statistical analyses}

We used a cohort study design linking exposure to ambient pollutant concentrations during each gestational month with birth weight. We excluded births with an estimated date of conception before 17 April 2004 or after 12 March 2016 to avoid fixed cohort bias [13].

Using generalized linear models, we regressed each subject's term birth weight $(\mathrm{g})$ against their mean $\mathrm{PM}_{2.5}$ concentration in the $1^{\text {st }}$ gestational month, adjusting for gestational age $(42,41,40,39,38$, or 37 weeks), year of birth (2005-2016), sex of infant, month of conception (January-December), parity $\left(1^{\text {st }}\right.$ birth, $2^{\text {nd }}$ birth, or $\geq 3^{\text {rd }}$ birth), maternal education (less than high school, high school or graduate, some college or more), maternal country of birth (United States or non-United States), maternal race (White, Black, other, mixed), maternal ethnicity (non-Hispanic or Hispanic), maternal tobacco use during pregnancy (yes or no), maternal drug use during pregnancy (yes or no), prepregnancy body mass index (BMI) categories (underweight: $<18.5 \mathrm{~kg} / \mathrm{m}^{2}$, healthy weight: $18.5-24.9 \mathrm{~kg} / \mathrm{m}^{2}$, overweight: $25.0-29.9 \mathrm{~kg} / \mathrm{m}^{2}$, Class I obesity: $30.0-34.9 \mathrm{~kg} / \mathrm{m}^{2}$, Class II obesity: $35.0-39.9 \mathrm{~kg} / \mathrm{m}^{2}$, Class III obesity: $\geq 40 \mathrm{~kg} / \mathrm{m}^{2}$ ), previous preterm birth (yes or no), previous cesarean section (yes or no), pre-pregnancy diabetes (yes or no), prepregnancy hypertension (yes or no), hospital of birth, trimester of first time prenatal visit $\left(1^{\text {st }}, 2^{\text {nd }}, 3^{\text {rd }}\right)$, primary provider of prenatal care (private physician, hospital outpatient, no provider), primary payer of prenatal care 
(Medicaid or family health plus or other government/child health plus B, private, self-pay, campus/Tricare or others), and mean temperature over the same gestational month. To determine what functional form of temperature should be included in the models, separate models were fit with temperature modeled either as a continuous variable (1 df) or using a natural spline with 2-4 degrees of freedom. A natural spline with 2 degrees of freedom had the lowest Akaike's Information Criterion value and was thus included in the model. From this model, we estimated the difference in term birth weight (and 95\% confidence interval) associated with each interquartile range (IQR) increase in mean $\mathrm{PM}_{2.5}$ concentration in the $1^{\text {st }}$ gestational month. We then reran this model for $\mathrm{PM}_{2.5}$ for each other gestational month (months $2,3,4,5,6,7,8,9)$ as well as the last month of pregnancy (i.e., last 31 days of pregnancy), and other pollutants (BC, UFP, AMP, $\mathrm{SO}_{2}, \mathrm{O}_{3}$ ).

Next, we explored whether the association between air pollution and term birth weight varied by maternal ethnicity (non-Hispanic or Hispanic), by adding interaction terms between the mean pollutant concentration and Hispanic to our model. Similarly, we examined effect modification of the pollutant/term birth weight association by maternal employment during pregnancy (employed or not employed) as well as the presence of pregnancy complications (i.e., gestational diabetes and/or gestational hypertension and eclampsia) and/or adverse birth conditions (i.e., fetus at risk or abnormal birth conditions).

\section{Sensitivity analyses}

Next, we separately added the mean $\mathrm{O}_{3}$ concentration from the same gestational month to each model with $\mathrm{PM}_{2.5}, \mathrm{BC}$, UFP, AMP, or $\mathrm{SO}_{2}$ to estimate the difference in term birth weight associated with each IQR increase in pollutant concentration, independent of ozone. Second, using logistic regression with $\mathrm{LBW}$ as the outcome and the same set of covariates as in the main analyses, we estimated the odds of LBW associated with each IQR increase in each mean pollutant concentration during each gestational month. Data management and descriptive analyses were conducted using SAS v.9.4 (SAS Inc., Cary, NC, USA), and all the GLM and logistic analyses were conducted using $\mathrm{R}$ (version 2.15.0).

\section{Results}

During the study period, there were 88,401 singleton live births in Monroe County compatible with the inclusion criteria. After excluding births with missing data for covariates included in our analytic models, we based our analyses of term birth weight on 76,500 subjects $(86.5 \%$ of the total included subjects). Among the study subjects, the mean term birth weight was $3431.6( \pm 471.6) \mathrm{g}$ and the overall percentage of term LBW infants was $2.15 \%$. As shown in Table 1, LBW was more common among women who were younger, non-white, Hispanic, with less education, and among women who reported use of tobacco, alcohol, or drugs during pregnancy. LBW babies were also more common among women with lower pre-pregnancy BMI, with a previous cesarean section, gestational hypertension, preeclampsia, or eclampsia, and for infants of smaller gestational age, who were female, born in the winter, the first baby of the mother, and with the first prenatal visit happening during late pregnancy.

The mean and interquartile range of pollutant concentrations and weather variables were similar across each gestational month (Supplementary Table 1). Correlation coefficients for pollutant concentrations across gestational months and for pollutants within a gestational month are shown in Supplementary Table 2. Across gestational months, mean $\mathrm{SO}_{2}$ concentrations were highly correlated $(0.781>r<0.902)$, while $\mathrm{BC}(0.251>r<0.737)$, UFP $(0.469>r<0.758)$, and AMP $(0.256>r<0.591)$ were moderately correlated. $\mathrm{PM}_{2.5}$ was only weakly correlated $(0.035>r<0.503)$, while $\mathrm{O} 3$ was more variable, likely due to across-season patterns $(-0.784>r<0.785)$. Within each gestational month, mean concentrations of $\mathrm{PM}_{2.5}$, BC, AMP, UFP, and $\mathrm{SO}_{2}$ were moderately correlated (e.g., Month 1: $0.431>r<0.719$ ), while $\mathrm{O}_{3}$ was only minimally correlated with any other pollutant (e.g., Month 1: $-0.162>r<0.161)$.

Inconsistent with our a priori hypothesis, increases in gestational month pollutant concentrations were generally not associated with decreased term birth weight among term births (Table 2). However, each IQR increase in BC concentration in the $1^{\text {st }}$ gestational month was associated with a $13.4 \mathrm{~g}$ increase in term birth weight $(95 \% \mathrm{CI}=3.4,23.4)$. Consistent with our a priori hypothesis, reduced term birth weight was associated with IQR increases in UFP concentrations in the $6^{\text {th }}$ gestational month $(-7.5 \mathrm{~g} ; 95 \%$ $\mathrm{CI}=-14.5,-0.4)$ and $7^{\text {th }}$ gestational month $(-6.3 \mathrm{~g}, 95 \%$ $\mathrm{CI}=-13.3,0.6)$, and increased $\mathrm{O}_{3}$ concentrations in the $1^{\text {st }}$ gestational month $(-15.8 \mathrm{~g}, 95 \% \mathrm{CI}=-31.5,-0.1)$. However, increased term birth weight was associated with IQR increases in mean $\mathrm{O}_{3}$ in the $7^{\text {th }}$ gestational month (17.2 g, 95\% CI = 3.1, 31.4).

There were also no clear patterns of effect modification of the air pollutant/term birth weight associations by infant gender (Table 3; Supplementary Table 3). However, among male infants, each IQR increase in $\mathrm{PM}_{2.5}$ concentration in the $3^{\text {rd }}$ gestational month was associated with a $5.6 \mathrm{~g}$ decrease in term birth weight $(95 \% \mathrm{CI}=-13.5,2.3)$, while among females it was associated with a $3.1 \mathrm{~g}$ increase $(95 \%$ $\mathrm{CI}=-4.8,11.0 ; p$-value for interaction $=0.024)($ Table 3$)$. 
Table 1 Infant, maternal, and health service use characteristics of the study subjects in Monroe County, by birth weight groups, 2005-2016 $(\mathrm{N}=76,500)$

\begin{tabular}{|c|c|c|}
\hline \multirow[t]{2}{*}{ Variable } & $\begin{array}{l}\text { Low birth weight } \\
(<2500 \mathrm{~g}) \\
(n=1644,2.1 \%)\end{array}$ & $\begin{array}{l}\text { Normal birth } \\
\text { weight }(\geq 25,000 \mathrm{~g}) \\
(n=74,856, \\
97.9 \%)\end{array}$ \\
\hline & $\%$ & $\%$ \\
\hline
\end{tabular}

INFANT CHARACTERISTICS

Gestational week

\begin{tabular}{|c|c|c|c|c|}
\hline 37 & 675 & 41.1 & 4642 & 6.2 \\
\hline 38 & 568 & 34.6 & 12,192 & 16.3 \\
\hline 39 & 313 & 19.0 & 27,082 & 36.2 \\
\hline 40 & 72 & 4.4 & 21,718 & 29.0 \\
\hline 41 & 16 & 1.0 & 8839 & 11.8 \\
\hline 42 & 0 & 0.0 & 383 & 0.5 \\
\hline \multicolumn{5}{|l|}{ Year of birth } \\
\hline 2005 & 115 & 7.0 & 5867 & 7.8 \\
\hline 2006 & 123 & 7.5 & 6607 & 8.8 \\
\hline 2007 & 112 & 6.8 & 6368 & 8.5 \\
\hline 2008 & 138 & 8.4 & 6757 & 9.0 \\
\hline 2009 & 154 & 9.4 & 6597 & 8.8 \\
\hline 2010 & 155 & 9.4 & 6623 & 8.9 \\
\hline 2011 & 153 & 9.3 & 6069 & 8.1 \\
\hline 2012 & 137 & 8.3 & 5584 & 7.5 \\
\hline 2013 & 145 & 8.8 & 6118 & 8.2 \\
\hline 2014 & 142 & 8.6 & 6119 & 8.2 \\
\hline 2015 & 147 & 8.9 & 6235 & 8.3 \\
\hline 2016 & 123 & 7.5 & 5912 & 7.9 \\
\hline \multicolumn{5}{|l|}{ Sex of infant } \\
\hline Male & 659 & 40.1 & 38,174 & 51.0 \\
\hline Female & 985 & 59.9 & 36,682 & 49.0 \\
\hline \multicolumn{5}{|l|}{ Season of conception } \\
\hline Spring & 403 & 24.5 & 17,236 & 23.0 \\
\hline Summer & 403 & 24.5 & 19,548 & 26.1 \\
\hline Fall & 423 & 25.7 & 19,872 & 26.6 \\
\hline Winter & 415 & 25.2 & 18,200 & 24.3 \\
\hline \multicolumn{5}{|l|}{ Season of birth } \\
\hline Spring & 407 & 24.8 & 19,480 & 26.0 \\
\hline Summer & 423 & 25.7 & 19,975 & 26.7 \\
\hline Fall & 412 & 25.1 & 18,552 & 24.8 \\
\hline Winter & 402 & 24.5 & 16,849 & 22.5 \\
\hline \multicolumn{5}{|l|}{ Month of conception } \\
\hline January & 136 & 8.3 & 6000 & 8.0 \\
\hline February & 122 & 7.4 & 5652 & 7.6 \\
\hline March & 121 & 7.4 & 5452 & 7.3 \\
\hline April & 135 & 8.2 & 5497 & 7.3 \\
\hline May & 147 & 8.9 & 6287 & 8.4 \\
\hline June & 114 & 6.9 & 6357 & 8.5 \\
\hline July & 131 & 8.0 & 6406 & 8.6 \\
\hline August & 158 & 9.6 & 6785 & 9.1 \\
\hline September & 142 & 8.6 & 6561 & 8.8 \\
\hline October & 156 & 9.5 & 6724 & 9.0 \\
\hline November & 125 & 7.6 & 6587 & 8.8 \\
\hline December & 157 & 9.6 & 6548 & 8.8 \\
\hline \multicolumn{5}{|l|}{ Parity } \\
\hline $1^{\text {st }}$ birth & 582 & 35.4 & 22,279 & 29.8 \\
\hline $2^{\text {nd }}$ birth & 377 & 22.9 & 21,444 & 28.7 \\
\hline $3^{\text {rd }}$ birth or higher & 685 & 41.7 & 31,133 & 41.6 \\
\hline Abnormal conditions of birth ${ }^{\mathrm{a}}$ & 358 & 21.8 & 9831 & 13.1 \\
\hline Fetus at risk ${ }^{\mathrm{b}}$ & 227 & 13.8 & 4544 & 6.1 \\
\hline
\end{tabular}

Table 1 (continued)

\begin{tabular}{|c|c|c|c|c|}
\hline \multirow[t]{2}{*}{ Variable } & \multicolumn{2}{|c|}{$\begin{array}{l}\text { Low birth weight } \\
(<2500 \mathrm{~g}) \\
(n=1644,2.1 \%)\end{array}$} & \multicolumn{2}{|c|}{$\begin{array}{l}\text { Normal birth } \\
\text { weight }(\geq 25,000 \mathrm{~g}) \\
(n=74,856, \\
97.9 \%)\end{array}$} \\
\hline & $n$ & $\%$ & $n$ & $\%$ \\
\hline \multicolumn{5}{|l|}{ MATERNAL CHARACTERISTICS } \\
\hline \multicolumn{5}{|l|}{ Maternal age } \\
\hline$<18$ & 60 & 3.7 & 1651 & 2.2 \\
\hline $18-29$ & 995 & 60.5 & 38,151 & 51.0 \\
\hline $30-39$ & 500 & 30.4 & 31,967 & 42.7 \\
\hline $40+$ & 52 & 3.2 & 2390 & 3.2 \\
\hline Unknown & 37 & 2.3 & 697 & 0.9 \\
\hline \multicolumn{5}{|l|}{ Maternal education } \\
\hline$<$ High School & 435 & 26.5 & 10,548 & 14.1 \\
\hline High school Graduate & 461 & 28.0 & 16,414 & 21.9 \\
\hline Some college or more & 748 & 45.5 & 47,894 & 64.0 \\
\hline \multicolumn{5}{|l|}{ Paternal education } \\
\hline$<$ High School & 244 & 14.8 & 7336 & 9.8 \\
\hline High school Graduate & 389 & 23.7 & 16,783 & 22.4 \\
\hline Some college or more & 537 & 32.7 & 39,843 & 53.2 \\
\hline Unknown & 474 & 28.8 & 10,894 & 14.6 \\
\hline \multicolumn{5}{|l|}{ Maternal country of birth } \\
\hline US & 1,484 & 90.3 & 66,797 & 89.2 \\
\hline Non-US & 160 & 9.7 & 8059 & 10.8 \\
\hline Maternal employed during pregnancy & 869 & 52.9 & 47,963 & 64.1 \\
\hline \multicolumn{5}{|l|}{ Maternal race } \\
\hline White & 770 & 46.8 & 52,376 & 70.0 \\
\hline Black & 653 & 39.7 & 14,743 & 19.7 \\
\hline Other & 166 & 10.1 & 6102 & 8.2 \\
\hline More than one & 55 & 3.4 & 1635 & 2.2 \\
\hline Maternal ethnicity (non-Hispanic) & 1,449 & 88.1 & 67,512 & 90.2 \\
\hline \multicolumn{5}{|l|}{ Maternal tobacco use } \\
\hline No & 1163 & 70.7 & 62,278 & 83.2 \\
\hline Yes & 481 & 29.3 & 12,578 & 16.8 \\
\hline \multicolumn{5}{|l|}{ Maternal alcohol use } \\
\hline No & 1589 & 96.7 & 73,254 & 97.9 \\
\hline Yes & 55 & 3.4 & 1583 & 2.1 \\
\hline Unknown & 0 & 0.0 & 19 & 0.0 \\
\hline \multicolumn{5}{|l|}{ Maternal drug use } \\
\hline No & 1361 & 82.8 & 70,128 & 93.7 \\
\hline Yes & 283 & 17.2 & 4728 & 6.3 \\
\hline \multicolumn{5}{|l|}{ Pre-pregnancy maternal BMI } \\
\hline Underweight $(<18.5 \mathrm{~kg} / \mathrm{m} 2)$ & 125 & 7.6 & 2465 & 3.3 \\
\hline Healthy $(18.5-24.9$ kg/m2) & 805 & 49.0 & 35,815 & 47.9 \\
\hline Overweight (25-29.9 kg/m2) & 359 & 21.8 & 18,526 & 24.8 \\
\hline Class I Obesity $(30-34.9 \mathrm{~kg} / \mathrm{m} 2)$ & 181 & 11.0 & 9558 & 12.8 \\
\hline Class II Obesity $(35-39.9 \mathrm{~kg} / \mathrm{m} 2)$ & 117 & 7.1 & 4834 & 6.5 \\
\hline Class III Obesity ( $\geq 40$ kg/m2) & 57 & 3.5 & 3658 & 4.9 \\
\hline Previous preterm infant & 135 & 8.2 & 2932 & 3.9 \\
\hline \multicolumn{5}{|l|}{ Previous cesarean section } \\
\hline No & 1434 & 87.2 & 63,776 & 85.2 \\
\hline Yes & 210 & 12.8 & 11,080 & 14.8 \\
\hline \multicolumn{5}{|l|}{ Mom's feeling toward this pregnancy } \\
\hline Could be sooner & 191 & 11.6 & 10,441 & 14.0 \\
\hline Just then & 591 & 36.0 & 34,662 & 46.3 \\
\hline Could be later & 481 & 29.3 & 16,556 & 22.1 \\
\hline Not want to be pregnant at all & 150 & 9.1 & 4109 & 5.5 \\
\hline Diabetes: pre-pregnancy & 17 & 1.0 & 595 & 0.8 \\
\hline Diabetes: gestational & 68 & 4.1 & 4183 & 5.6 \\
\hline Hypertension: pre-pregnancy & 75 & 4.6 & 1653 & 2.2 \\
\hline Gestational hypertension/preeclampsia & 223 & 13.6 & 4485 & 6.0 \\
\hline Eclampsia & 8 & 0.5 & 46 & 0.1 \\
\hline
\end{tabular}


Table 1 (continued)

\begin{tabular}{|c|c|c|c|c|}
\hline \multirow[t]{2}{*}{ Variable } & \multicolumn{2}{|c|}{$\begin{array}{l}\text { Low birth weight } \\
(<2500 \mathrm{~g}) \\
(n=1644,2.1 \%)\end{array}$} & \multicolumn{2}{|c|}{$\begin{array}{l}\text { Normal birth } \\
\text { weight }(225,000 \mathrm{~g} \\
(n=74,856, \\
97.9 \%)\end{array}$} \\
\hline & $n$ & $\%$ & $n$ & $\%$ \\
\hline \multicolumn{5}{|l|}{ HEALTH SERVICE FACTORS } \\
\hline \multicolumn{5}{|l|}{ Hospital at birth } \\
\hline Hospital_A & 472 & 28.7 & 25,253 & 33.7 \\
\hline Hospital_B & 253 & 15.4 & 11,545 & 15.4 \\
\hline Hospital_C & 395 & 24.0 & 18,617 & 24.9 \\
\hline Hospital_D & 511 & 31.1 & 18,741 & 25.0 \\
\hline Hospital_Other & 13 & 0.8 & 700 & 0.9 \\
\hline \multicolumn{5}{|l|}{ Trimester for first prenatal visit } \\
\hline 1st trimester & 1122 & 68.3 & 59,244 & 79.1 \\
\hline 2nd trimester & 437 & 26.6 & 13,405 & 17.9 \\
\hline 3rd trimester & 85 & 5.2 & 2207 & 3.0 \\
\hline \multicolumn{5}{|l|}{ Primary provider of prenatal care } \\
\hline Private physician & 1096 & 66.7 & 61,572 & 82.3 \\
\hline Hospital outpatient & 547 & 33.3 & 13,254 & 17.7 \\
\hline No provider & 1 & 0.1 & 30 & 0.0 \\
\hline \multicolumn{5}{|l|}{ Primary payer for birth } \\
\hline $\begin{array}{l}\text { Medicaid, Family Health Plus, Child } \\
\text { Health Plus }\end{array}$ & 947 & 57.6 & 27,725 & 37.0 \\
\hline Private & 669 & 40.7 & 45,962 & 61.4 \\
\hline Self-pay & 17 & 1.0 & 462 & 0.6 \\
\hline Champus/Tricare & 4 & 0.2 & 411 & 0.6 \\
\hline Others & 7 & 0.4 & 296 & 0.4 \\
\hline \multicolumn{5}{|l|}{ Medicaid secondary payer } \\
\hline No & 1522 & 92.6 & 70,290 & 93.9 \\
\hline Yes & 71 & 4.3 & 2466 & 3.3 \\
\hline Unknown & 51 & 3.1 & 2100 & 2.8 \\
\hline \multicolumn{5}{|l|}{ Prenatal participation in WIC } \\
\hline No & 686 & 41.7 & 47,400 & 63.3 \\
\hline Yes & 928 & 56.5 & 26,584 & 35.5 \\
\hline Unknown & 30 & 1.8 & 872 & 1.2 \\
\hline \multicolumn{5}{|c|}{ Participation in $\mathrm{HMO}$ or other managed care plan } \\
\hline No & 774 & 47.1 & 41,970 & 56.1 \\
\hline Yes & 834 & 50.7 & 31,245 & 41.7 \\
\hline Unknown & 36 & 2.2 & 1641 & 2.2 \\
\hline
\end{tabular}

${ }^{\mathrm{a}}$ Abnormal conditions of birth: including assisted ventilation required immediately following delivery, assisted ventilation required for more than $6 \mathrm{~h}$, NICU Admission ( $>4 \mathrm{~h}$ ), newborn given surfactant replacement therapy, antibiotics received by the newborn for suspected neonatal sepsis, seizures or serious neurologic dysfunction, significant birth injury (Skeletal fx, peripheral nerve injury, soft tissue/solid organ hemorrhage) which requires intervention

${ }^{b}$ Fetus at Risk: reasons under indications for intervention (C-section, vacuum or forceps delivery) - In general, to mark "Fetus at Risk" there has to be an abnormal electronic fetal heart tracing and/or combined with an abnormal ultrasound: evidence from a biophysical profile of a disturbance in utero; positive contraction stress test, the presence of late decelerations, during oxytocin stimulation with half or more of the contractions; breech or a mal-presentation such as transverse lie, shoulder presentation; frank prolapse of the cord; fetal structural anomaly, such as fetal hydrocephalus; persistent late decelerations during most contractions; persistent variable decelerations during most contractions, often 60 to $80 \mathrm{bpm}$; prolonged bradycardia below 110 to $100 \mathrm{bpm} 10 \mathrm{~min}$ or longer; prolonged tachycardia above 160 to 180 bpm persisting longer than $10 \mathrm{~min}$; fetal scalp $\mathrm{pH}$ of less than 7.2. Includes acidosis

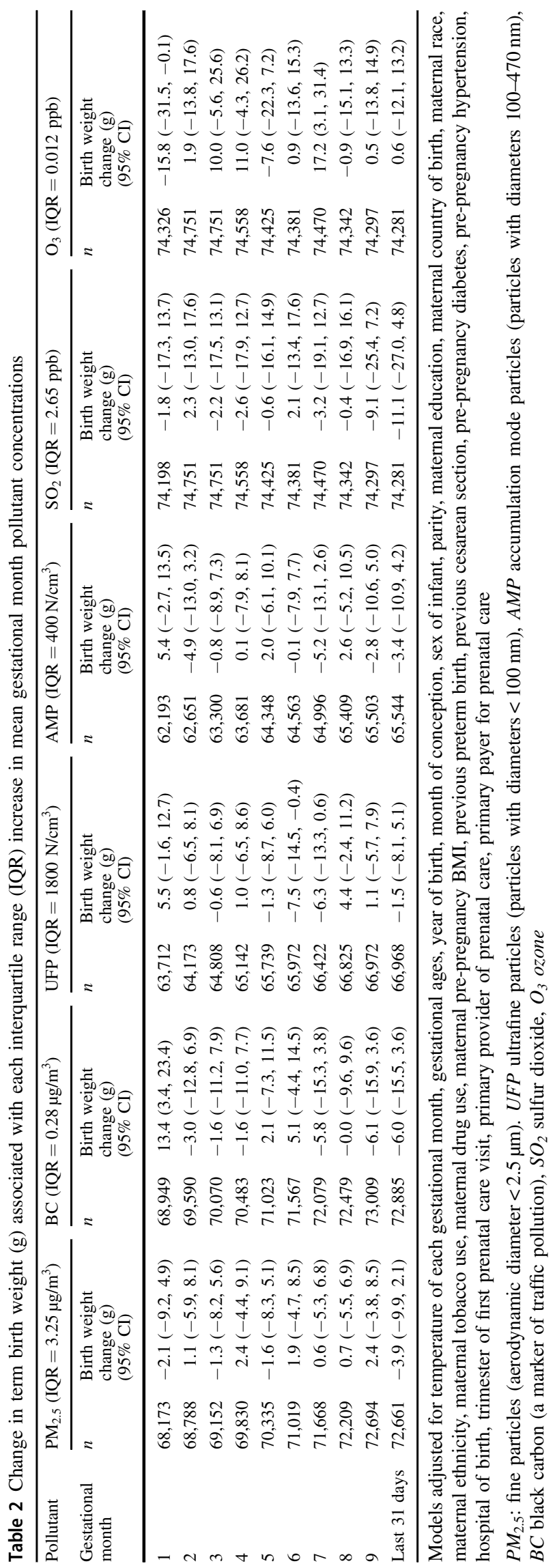




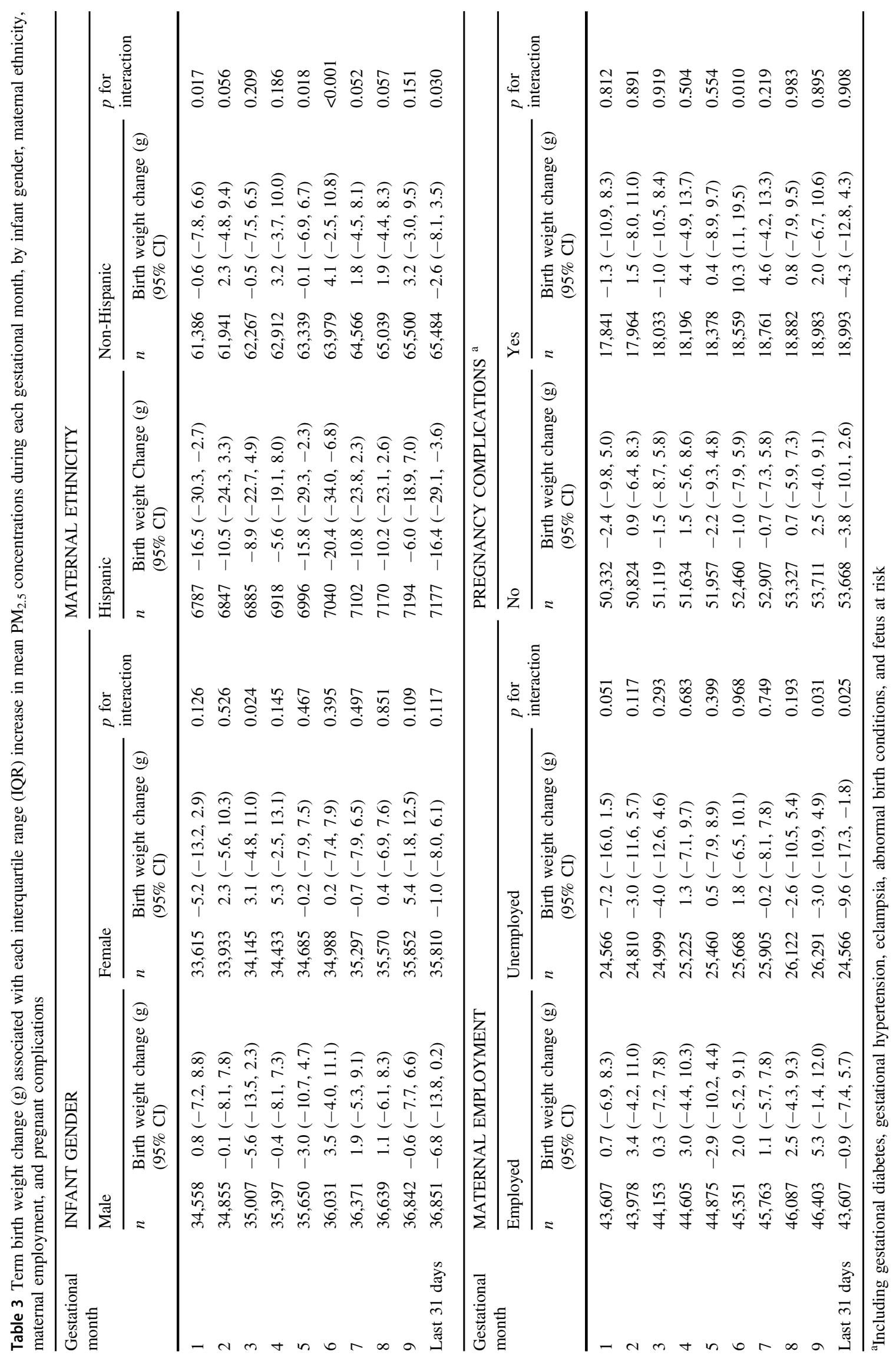


Although there was no clear pattern of effect modification by pregnancy complications (Table 3, Supplementary Table 4), among pregnancies with complications each IQR increase in $\mathrm{PM}_{2.5}$ concentration in the $6^{\text {th }}$ gestational month was associated with a significantly $(p=0.010)$ greater increase in term birth weight $(10.3 \mathrm{~g} ; 95 \% \mathrm{CI}=1.1,19.5)$ than in those pregnancies without complications $(-1.0 \mathrm{~g}$; $95 \% \mathrm{CI}=-7.9,5.9)$ (Table 4). Among pregnancies where the mother was unemployed, decreases in term birth weight associated with IQR increases in $\mathrm{PM}_{2.5}$ concentration in the last 31 days $(-9.6 \mathrm{~g} ; 95 \% \mathrm{CI}=-17.3,-1.8)$ were significantly $(p=0.025)$ larger in magnitude than among employed mothers $(-0.9 \mathrm{~g}$; 95\% CI $=-7.4,5.7)$ (Table 3). IQR increases in $\mathrm{PM}_{2.5}$ concentration in the $1^{\text {st }}$ and $9^{\text {th }}$ months followed similar patterns, but there was no pattern of effect modification of associations between other pollutants and term birth weight (Supplementary Table 5). However, there were clear differences in term birth weight changes associated with IQR increases in mean $\mathrm{PM}_{2.5}$ concentrations in multiple gestational months for Hispanic versus non-Hispanic women (e.g., Month 1-non-Hispanic: $0.6 \mathrm{~g}, 95 \% \mathrm{CI}=-7.8$, 6.6; Hispanic: $-16.5 \mathrm{~g}, 95 \% \mathrm{CI}=$ $-30.3,-2.7 ; p=0.017$; Table 4). Similar patterns of effect modification by ethnicity were observed for all other pollutants at most gestational months, except $\mathrm{O}_{3}$ (Supplementary Table 6).

When adjusting for the mean $\mathrm{O}_{3}$ concentration in the same gestational month, we did not observe any associations between IQR increases in pollutant concentrations and term birth weight, except for $\mathrm{BC}$ during the $1^{\text {st }}$ gestational month $\left(\mathrm{IQR}=0.28 \mu \mathrm{g} / \mathrm{m}^{3} ; 11.6 \mathrm{~g}, 95 \% \mathrm{CI}=1.5,21.7\right)$ (Supplementary Table 7). Similar to our main analysis findings with term birth weight as the outcome, we did not find any increased odds of LBW associated with IQR increases in concentrations of any pollutant during any gestational month (Table 4).

\section{Discussion}

Using a large dataset combining birth certificates and maternal and infant hospital discharge data in the Finger Lakes region of New York State and 12 years of air pollution monitoring data, we did not find consistent associations between term birth weight and concentrations of any pollutant (i.e., $\mathrm{PM}_{2.5}, \mathrm{BC}$, UFP, $\mathrm{AMP}, \mathrm{SO}_{2}$, and $\mathrm{O}_{3}$ ) during any gestational month, after adjustment for numerous maternal, infant and birth characteristics, and temporal factors (i.e., season and long term time trend). Results were similar after additional adjustment for ambient $\mathrm{O}_{3}$ concentrations, as well as when estimating pollutant effects on the odds of LBW. There were no differences in term birth weight changes associated with air pollutants by maternal
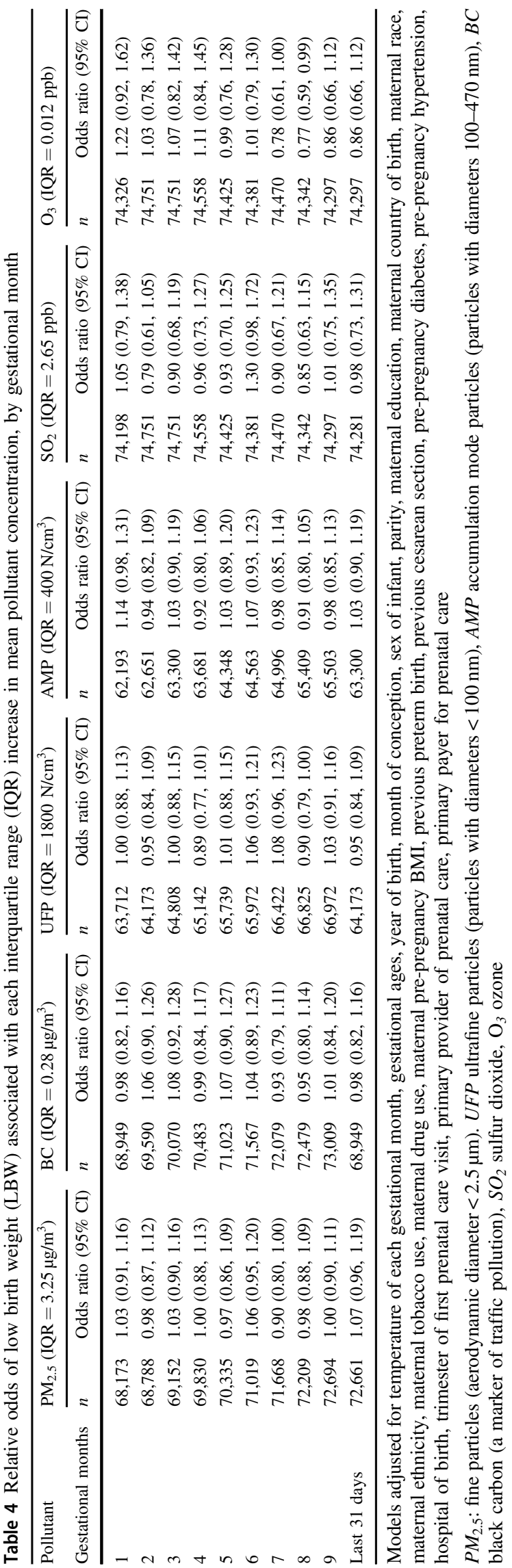
employment during pregnancy, pregnancy complications, adverse birth conditions, or infant gender. However, infants born to unemployed mothers had slightly larger reductions in term birth weight associated with increased pollutant concentrations than employed mothers. Further, across all gestational months and multiple pollutants, we observed large decreases in term birth weight associated with increased gestational month pollutant concentrations among Hispanic mothers, but not among non-Hispanic mothers.

Our finding of no association between air pollution levels during pregnancy and term birth weight among term birth is inconsistent with most previous studies. A pooled analysis of 14 European birth cohort studies reported a $-7 \mathrm{~g}$ reduction in term birth weight $(95 \% \mathrm{CI}=-17,2)$ associated with each $5 \mu \mathrm{g} / \mathrm{m}^{3}$ increase in $\mathrm{PM}_{2.5}$ concentration across the entire pregnancy [4]. An increased risk of LBW associated with increased gestational PM pollutant concentrations was reported in a meta-analyses of multicontinent studies [5]. In the United States, an increased risk of LBW was associated with $\mathrm{PM}_{2.5}$ concentrations in both early and late pregnancy $\left(1^{\text {st }}\right.$ and $3^{\text {rd }}$ trimesters in a New Jersey study [14]. In Massachusetts and Connecticut, each $2.2 \mu \mathrm{g} / \mathrm{m}^{3}$ increase in $\mathrm{PM}_{2.5}$ concentrations during pregnancy was associated with a $-14.7 \mathrm{~g}$ reduction $(-17.1$ to $-12.3)$ in birth weight among term births (37-42 gestational weeks) [15]. In Beijing, interquartile range increases in air pollutant concentrations during the $8^{\text {th }}$ month were associated with $17 \mathrm{~g}$ to $34 \mathrm{~g}$ reductions in term birth weight among term births. In the same study, pregnancies with their $8^{\text {th }}$ gestational months during the 2008 Beijing Olympics (and its large declines in air pollutant concentrations during the Games) were $23 \mathrm{~g}$ larger $(95 \% \mathrm{CI}=$ $5,40)$ than pregnancies with their $8^{\text {th }}$ months of pregnancy during the same calendar dates in 2007 or 2009 [9]. However, other studies reported no such associations [7].

With regards to other studies of air pollution and birth outcomes in residents of New York State, our findings are consistent with those of Brown et al. [16], who found no association between exposure to $\mathrm{PM}_{2.5}$ during pregnancy and term LBW. Previously, in Rochester NY, Pereira et al. reported that elevated ambient $\mathrm{PM}_{2.5}$ levels during pregnancy were associated with an increased odds of preterm birth, but not pre-labor rupture of membranes [11]. In another study examining the association between ambient pollutants and hypertensive disorder of pregnancy in New York City, no association was found between $\mathrm{PM}_{2.5}$ or $\mathrm{NO}_{2}$ concentrations and gestational hypertension [17]. Thus, the role of ambient air pollution exposure during pregnancy in New York State on birth outcomes remains unclear.

Our findings of no effect modification by infant gender is consistent with some studies [8, 18], but not another [19] who reported that each $\sim 30 \mu \mathrm{g} / \mathrm{m}^{3}$ increase in $\mathrm{PM}_{2.5}$ concentration during gestation was associated with a $189 \mathrm{~g}$ deficit in male newborns, but only a $17 \mathrm{~g}$ deficit in female newborns.[19] In a systematic review, Ghosh et al. [20] reported a higher prevalence of LBW at birth among female than male infants, but a higher risk of LBW associated with pollutant concentrations among male infants.

Our finding of decreased term birth weight associated with increased concentrations of multiple pollutants among Hispanic mothers, but not non-Hispanic mothers, may be due to several factors. Some have reported that mothers with lower socio-economic status are more vulnerable to air pollution exposure during pregnancy due in part to having residences in areas of high air pollution, and/or longer times spent commuting and thus higher traffic pollution exposures $[4,21]$. Further, they argue that these mothers are also more likely to have lower birth weight and a higher risk of LBW [4, 21]. Another explanation might be different degrees of exposure misclassification for Hispanic and non-Hispanic mothers. Using GIS, we mapped the residence of each mother in our study, and found that Hispanic mothers, both those born in the US (median residential distance from DEC site $=4.45$ miles) and not born in the United States (median distance $=5.13$ miles) generally lived closer to the monitoring station than non-Hispanic mothers born in the US (median distance $=$ 5.87 miles) and non-Hispanic mothers not born in the United States (median distance $=5.41$ miles; Fig. 1). Thus, the $\mathrm{PM}_{2.5}$ concentrations from the monitoring location may be better estimates of Hispanic mothers' exposures to ambient $\mathrm{PM}_{2.5}$ during pregnancy than non-Hispanic mothers (i.e., less exposure error), resulting in less underestimation of effect estimates for Hispanic mothers than non-Hispanic mothers. Thus, this may, in part, explain our findings.

Although our study had several strengths including a large sample size with resulting increased statistical power, and the use of a detailed database of linked birth certificates and hospital admissions data, there are several limitations that should be considered when making inference. First, we used pollution data from the single central monitoring site as the proxy for each pregnant woman's individual exposure to air pollution during pregnancy, but study subjects lived a median of 5.65 miles from the monitoring station $\left(5^{\text {th }}\right.$ percentile $=1.80$ miles, $95^{\text {th }}$ percentile $=15.67$ miles $)$. Thus, this likely resulted in non-differential exposure misclassification and underestimates of the true effects. Our previous work has suggested spatial heterogeneity in the $\mathrm{PM}_{2.5}$ concentrations across Rochester [22]. However, other pollutants may be more spatially heterogeneous [23-26]. Further, there are other modifiers of air pollution exposure (e.g., time spent indoors versus outdoors) that all could have resulted in non-differential exposure misclassification and effect underestimation. Second, tobacco use, alcohol consumption and drug use were collected through self-report and therefore may be underreported. Although this may lead to residual confounding by these factors, there were other 


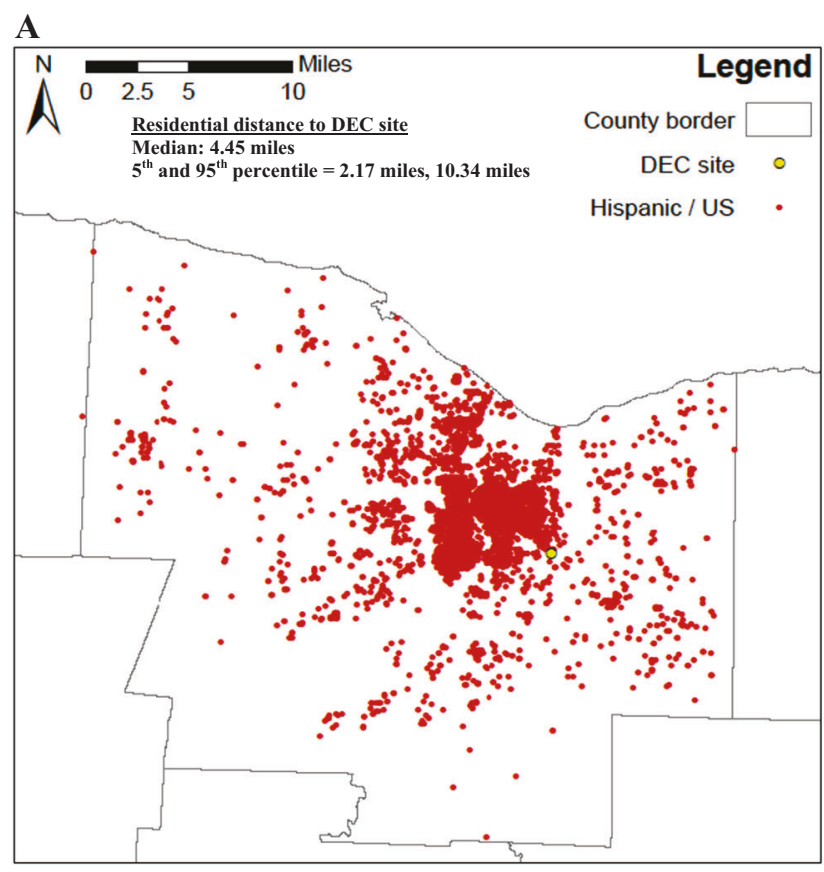

C

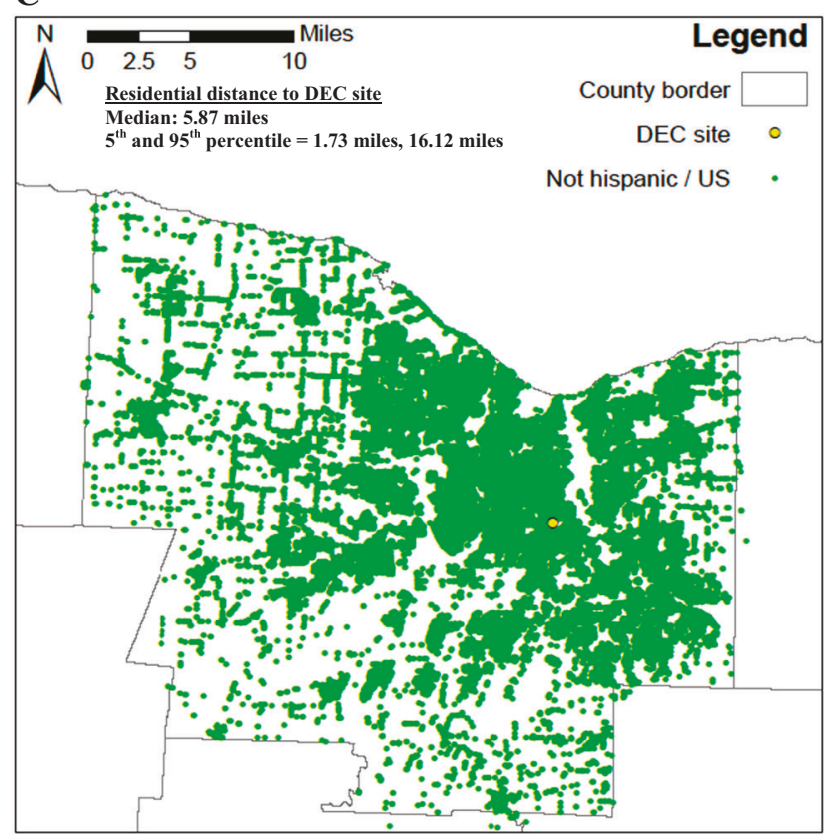

Fig. 1 Residence of each study subject, separately for: a Hispanic mothers who were born in the United States. b Hispanic mothers who were not born in the United States. c Non-Hispanic mothers who were

SES covariates included in the analysis (some of which are likely correlated with tobacco, alcohol, and drug use). Thus, residual confounding by these factors is likely minimal. Third, although we ran many models, our inference was based largely on the overall pattern of term birth weight changes associated with increased pollution concentrations across gestational months, and not on whether each individual effect estimate was statistically significant.

\section{B}

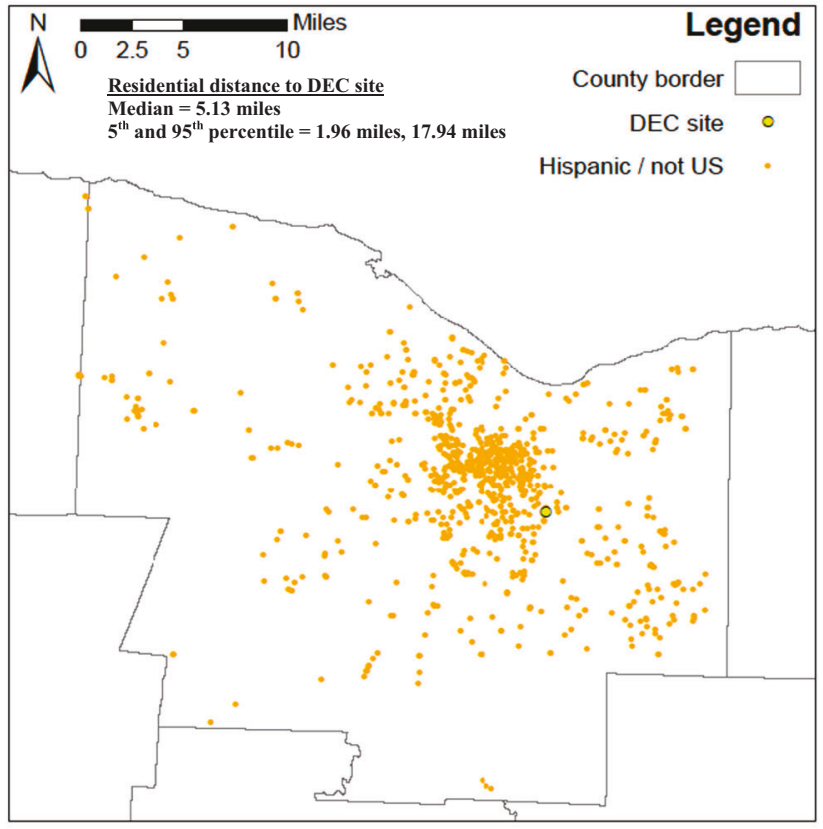

D

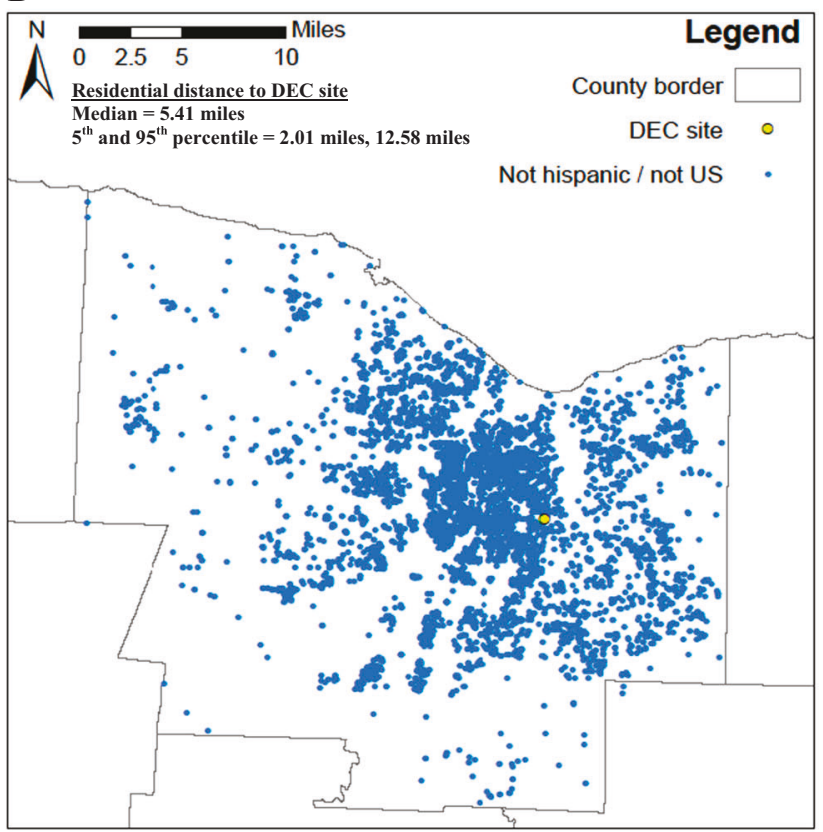

born in the United States. d Non-Hispanic mothers who were not born in the United States

In summary, among pregnant women of Monroe County, New York from 2005 to 2016, we found no clear patterns of term birth weight change associated with increased concentrations of any pollutant across gestational months. Further, there were no patterns of effect modification by infant gender, pregnancy complications, or season. However, among Hispanic women only, increases in all pollutants, except $\mathrm{O}_{3}$, in multiple gestational months, were associated with 
decreased term birth weight. This may be a result of different degrees of exposure misclassification due to residential proximity to the air pollutant monitoring site, but further work is needed to understand these differences by ethnicity.

Acknowledgements This work was funded by the New York State Energy Research and Development Authority (Contract \#'s: 59800 and 59802) and the National Institutes of Environmental Health Sciences Grant \# P30 ES001247. DC was supported by the National Institute of Health training grant (T32 HL066988-1).

\section{Compliance with ethical standards}

Conflict of interest The authors declare that they have no conflict of interest.

Publisher's note: Springer Nature remains neutral with regard to jurisdictional claims in published maps and institutional affiliations.

Open Access This article is licensed under a Creative Commons Attribution 4.0 International License, which permits use, sharing, adaptation, distribution and reproduction in any medium or format, as long as you give appropriate credit to the original author(s) and the source, provide a link to the Creative Commons license, and indicate if changes were made. The images or other third party material in this article are included in the article's Creative Commons license, unless indicated otherwise in a credit line to the material. If material is not included in the article's Creative Commons license and your intended use is not permitted by statutory regulation or exceeds the permitted use, you will need to obtain permission directly from the copyright holder. To view a copy of this license, visit http://creativecommons. org/licenses/by/4.0/.

\section{References}

1. Trasande L, Wong K, Roy A, Savitz DA, Thurston G. Exploring prenatal outdoor air pollution, birth outcomes and neonatal health care utilization in a nationally representative sample. J Expo Sci Environ Epidemiol. 2013;23:315-21.

2. Sun X, Luo X, Zhao C, Zhang B, Tao J, Yang Z, et al. The associations between birth weight and exposure to fine particulate matter (PM2.5) and its chemical constituents during pregnancy: A meta-analysis. Environ Pollut. 2016;211:38-47.

3. Lamichhane DK, Leem JH, Lee JY, Kim HC. A meta-analysis of exposure to particulate matter and adverse birth outcomes. Environ Health Toxicol. 2015;30:e2015011.

4. Pedersen M, Giorgis-Allemand L, Bernard C, Aguilera I, Andersen A-MN, Ballester F, et al. Ambient air pollution and low birthweight: a European cohort study (ESCAPE). Lancet Respir Med. 2013;1:695-704.

5. Dadvand P, Parker J, Bell ML, Bonzini M, Brauer M, Darrow LA, et al. Maternal exposure to particulate air pollution and term birth weight: a multi-country evaluation of effect and heterogeneity. Environ Health Perspect. 2013;121:267-373.

6. Stieb DM, Chen L, Eshoul M, Judek S. Ambient air pollution, birth weight and preterm birth: a systematic review and metaanalysis. Environ Res. 2012;117:100-11.

7. Parker JD, Rich DQ, Glinianaia SV, Leem JH, Wartenberg D, Bell ML, et al. The International Collaboration on Air Pollution and Pregnancy Outcomes: initial results. Environ Health Perspect. 2011;119:1023-8.
8. Pedersen M, Giorgis-Allemand L, Bernard C, Aguilera I, Andersen AM, Ballester F, et al. Ambient air pollution and low birthweight: a European cohort study (ESCAPE). Lancet Respir Med. 2013;1:695-704.

9. Rich DQ, Liu K, Zhang J, Thurston SW, Stevens TP, Pan Y, et al. Differences in birth weight associated with the 2008 Beijing olympics air pollution reduction: results from a natural experiment. Environ Health Perspect. 2015;123:880-7.

10. Woodruff TJ, Parker JD, Darrow LA, Slama R, Bell ML, Choi H, et al. Methodological issues in studies of air pollution and reproductive health. Environ Res. 2009;109:311-20.

11. Pereira G, Evans KA, Rich DQ, Bracken MB, Bell ML. Fine particulates, preterm birth, and membrane rupture in rochester, NY. Epidemiology. 2016;27:66-73.

12. Assibey-Mensah V. Ambient particulate matter air pollution and the risk of hypertensive disorders of pregnancy in Monroe County. New York: University of Rochester School of Medicine and Dentistry; 2017.

13. Strand LB, Barnett AG, Tong S. Methodological challenges when estimating the effects of season and seasonal exposures on birth outcomes. BMC Med Res Methodol. 2011;11:49.

14. Rich DQ, Demissie K, Lu SE, Kamat L, Wartenberg D, Rhoads GG. Ambient air pollutant concentrations during pregnancy and the risk of fetal growth restriction. J Epidemiol Community Health. 2009;63:488-96.

15. Bell ML, Ebisu K, Belanger K. Ambient air pollution and low birth weight in Connecticut and Massachusetts. Environ Health Perspect. 2007;115:1118-24.

16. Brown JM, Harris G, Pantea C, Hwang SA, Talbot TO. Linking air pollution data and adverse birth outcomes: environmental public health tracking in New York State. J Public Health Manag Pract: Jphmp. 2015;21(Suppl 2):S68-74.

17. Savitz DA, Elston B, Bobb JF, Clougherty JE, Dominici F, Ito K, et al. Ambient fine particulate matter, nitrogen dioxide, and hypertensive disorders of pregnancy in New York City. Epidemiology. 2015;26:748-57.

18. Bell ML, Ebisu K, Belanger K. The relationship between air pollution and low birth weight: effects by mother's age, infant sex, copollutants, and pre-term births. Environ Res Lett. 2008;3:44003.

19. Jedrychowski W, Perera F, Mrozek-Budzyn D, Mroz E, Flak E, Spengler JD, et al. Gender differences in fetal growth of newborns exposed prenatally to airborne fine particulate matter. Environ Res. 2009;109:447-56.

20. Ghosh R, Rankin J, Pless-Mulloli T, Glinianaia S. Does the effect of air pollution on pregnancy outcomes differ by gender? A systematic review. Environ Res. 2007;105:400-8.

21. Westergaard N, Gehring U, Slama R, Pedersen M. Ambient air pollution and low birth weight-are some women more vulnerable than others? Environ Int. 2017;104:146-54.

22. Zikova N, Masiol M, Chalupa DC, Rich DQ, Ferro AR, Hopke PK. Estimating hourly concentrations of PM2.5 across a Metropolitan area using low-cost particle monitors. Sensors (Basel). 2017;17(8).

23. Wang Y, Hopke PK, Utell MJ. Urban-scale spatial-temporal variability of black carbon and winter residential wood combustion particles. Aerosol Air Quality Research. 2011;11:473-81.

24. Wang Y, Hopke PK, Utell MJ. Urban-scale seasonal and spatial variability of ultrafine particle number concentrations. Water Air Soil Pollution. 2012;223:2223-35.

25. Masiol M, Squizzato S, Chalupa D, Rich DQ, Hopke PK. Spatiotemporal variations of ozone concentrations across a metropolitan area using a network of low-cost monitors and an hourly land-use regression model. Sci Total Environ. 2019;654:1167-78.

26. Su J, Hopke PK, Tian Y, Baldwin N, Thurston S, Evans K, et al. Modeling particulate matter concentrations measured through mobile monitoring in a machine learning approach. Atmos Environ. 2015;122:477-83. 